\title{
UAV/UGV System for meso-macro pollutants identification in the beach environment
}

\author{
Cosimo Cagnazzo (1), Ettore Potente (1), Hervé Regnauld (2), \\ Sabino Rosato (3) \& Giuseppe Mastronuzzi (1)
}

(1) Department of Earth and Geoenvironmental Science, University of Bari - 70121, Bari, Italy.

(2) LETG, University of Rennes 2 - 35043, Rennes, France.

(3) Serveco Srl - 74020, Montemesola, Italy.

Corresponding author e-mail: cosimo.cagnazzo@uniba.it

Document type: Short note.

Manuscript received 19 April 2021; accepted 07 October 2021; editorial responsibility and handling by M. Menichini.

\section{ABSTRACT}

Direct and indirect pressure of anthropic activities in the immediate vicinity of the coastal strip increase the potential for environmental pollution. Given the extension of the areas, detailed investigations and early warning might result difficult, therefore scientific research and technological innovation in recent years is developing, more efficient and faster methodologies for the early identification of possible pollution situations that are dangerous for the entire ecosystem.

We present the results of a research project that aims to develop an integrated system consisting of an air vehicle (UAV - Unmanned Air Vehicle) and ground vehicle (UGV - Unmanned Ground Vehicle), equipped with a variety of sensors, that is able to rapidly detect the presence of various pollutants along the coastal strip. The system was developed within a PhD research project in Geosciences of the $33^{\text {rd }}$ PON cycle of the University of Bari

All phases of field experimentation of the methodology were carried out in three coastal areas and in particular in the Regional Park of the Coastal Dunes of Ostuni (BR), in the WWF Oasis Bosco Pantano di Policoro (MT) and on the coastal strip between Portsall and Lampaul-Ploudalmezeau in the Brittany region (France).

The ground vehicle designed, prototyped and tested, represents one of the most important products of the research project.

KEY WORDS: Beach Litter, Oil beaching, Oil spill, Infrared Thermography, Multispectral Survey, GIS, Coastal Pollution, Coastal Environmental Risk, UAV, UGV;

\section{INTRODUCTION}

Over the years, the increasing urban and industrial development that has interested maritime and coastal areas determined an increasing risk of environmental pollution. Since the second half of the twentieth century there have been serious environmental disasters at sea affecting, after a few days, the entire coastal system. The oil spill caused by wrecking of the oil tanker Amoco Cadiz on the coast of Brittany, France, in 1978 tragically remains one of the most important environmental disastersin the records (D'Ozouville et al., 1978; Marchand, 1980; Atlas et al., 1981; Conan, 1982; Marchand et al., 1982; Gundlach et al., 1983), involving 90 coastal municipalities. They suffered extensive damage to the entire coastal ecosystem caused by the oil slick spilled into the sea and beached along the shores of Brittany. It took about 6 months to clean up the affected shores.

In addition to oil spills, the coasts are continuously threatened by the inputs of materials originating from antrophic activities on land and transported/vehiculated to the sea by surface water flows.

Furthermore, with the expansion of the production and the commerce of plastic material, the presence and dispersion of marine litter throughout the coastal area is becoming dramatic. All this, over time, can determine the loss of value of the coastal ecosystem (tourist or protected areas, lagoons, rocky coasts, fish farms).

In order to improve the capacity on the investigation of environmental pollution, over the last decades, development and technological innovation considerably improved timely environmental monitoring in order to permit quick actions to limit damages to the coastal ecosystem. From this point of view, the launch of satellites dedicated to large-scale environmental monitoring has given considerable help (Khanna et al., 2018; Giuliani et al., 2019). On a small-medium spatial scale, for some years now, the use of UAVs equipped with appropriate sensors (RGB camera, thermal camera, multispectral camera) has become increasingly important in environmental surveillance (Lega et al., 2010; Lega et al., 2012; Cagnazzo et al., 2020; De Giglio et al., 2020).

In some situations, UAV surveillance is anticipated by modelling simulations that allow to predict possible coastal pollution due to environmental disasters. (Zanier et al., 2019; Cagnazzo et al., 2020; Manning et al., 2021).

The use of these new sensors and these software components were the basis of the methodologies developed into the PhD research project called SIAT. Furthermore, also considering the growing impact in the use of robotics, a UGV was designed, built and tested capable of moving in a beach environment. A Ground Station ensured interaction and communication between the UAV and the UGV (custom built). The Ground Station allowed the preprocessing of UAV images, which was the fundamental step for the subsequent planning of the ground mission by the UGV in order to better identify, compared to the UAV 
surveys, the polluting material. Two of the test sites of this project belong to coastal areas protected by the current Italian national legislation for nature conservation. They are the (i) Regional Park of the Coastal Dunes of Ostuni (BR) and the (ì) WWF Oasis Bosco Pantano di Policoro (MT). A Further testing activity was performed on the coastal area between Portsall and Lampaul-Ploudalmezeau in the Brittany-France region (Fig. 1) that was heavily impacted by the oil spill of Amoco Cadiz in 1978.

The paper summarizes all the research activities carried out during the three years of the XXXIII PON cycle of the $\mathrm{PhD}$ in Geosciences. The research project was carried out in collaboration with the University of Bari, with Serveco Srl and the LETG CNRS (Littoral, Environnement, Télédétection, Géomatique CNRS) in Rennes (France).

\section{GEOLOGICAL AND GEOMORPHOLOGICAL SETTING OF STUDY AREAS}

The Coastal Dunes Park is located on the Apulian coast in the southern Adriatic Sea and stretches for $6 \mathrm{~km}$ from Torre Canne to Torre San Leonardo (Brindisi). The area hosts a coastal dune system parallel to shoreline and characterized by the presence of several coastal lakes and ponds. Individual dunes can reach a height of up to $17 \mathrm{~m}$.

The dune system is formed by medium sand deposits comprising carbonates, quartz and other minerals in very low percentages (pyroxene, feldspar); rare fragments of siliciclastic rocks are also present. (Mastronuzzi et al, 2001; Mastronuzzi et al, 2002; Moretti et al., 2016). The wind regime in the whole coastal sector (reigning and dominant) is mainly from the northern quadrant. In the winter months, storm surges are very frequent causing erosion and the beaching of inorganic and organic materials of from natural and anthropic origins. The trend of currents along the coast follows the main direction of the coast (NW-SE) and affects sediment transport (Mastronuzzi et al., 2002).

The WWF oasis "Bosco Pantano" is located on the Ionian Sea coast of Basilicata between the Sinni and the Agri river mouths (Matera). The whole coastal area has a SW-NE orientation and is bordered inland by a staircase of terraced marine deposits from the MiddleUpper Pleistocene (Sauer et al., 2010; De Santis et al., 2018; De Santis et al., 2019). The mobile coastal system is characterized by a dune belt with heights reaching $13 \mathrm{~m}$. South-easterly winds dominate the area with an average speed of $8.69 \mathrm{~ms}^{-1}$ (Cilumbriello et al., 2010; Sabato et al., 2012). The direction of the sea currents (Aiello et al., 2013) has been identified by many scientific researches considering the sedimentological features. In particular, sediments are transported towards the NE (Brondi et al., 1974; Benassai et al., 1976; Belfiore, 1984).

The geology of the coast of Brittany, France, is characterized by the presence of ancient igneous and metamorphic rocks (granite and migmatites) which are the result of a complex deformation history. The resistant nature of these rocks to erosive processes connected to the sea level rise during the Holocene and the present marine dynamics have shaped numerous promontories and coastal islands interspersed with pocket beaches. The high tidal

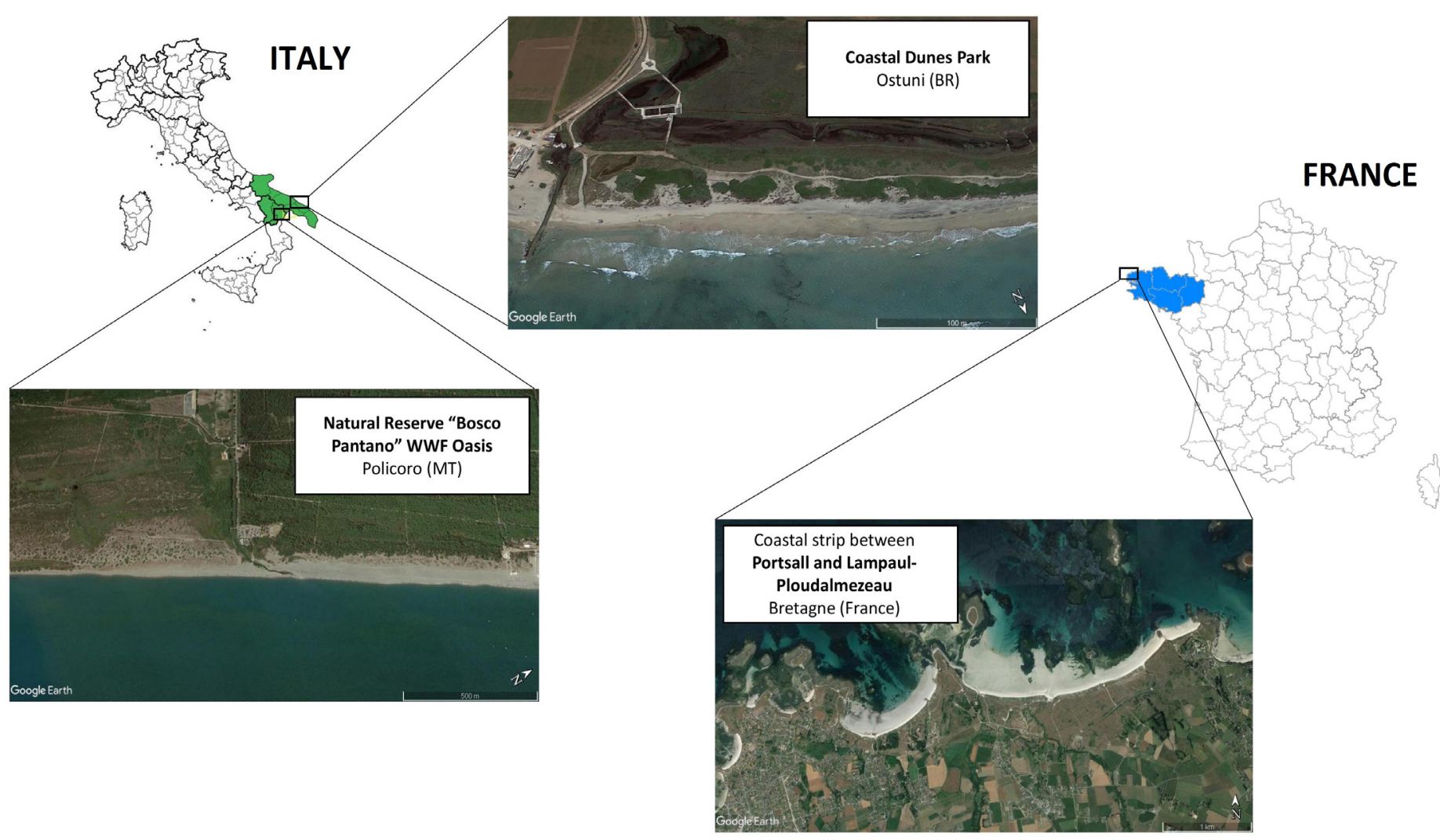

Fig. 1 - Study areas location of PhD Research Project. 
excursions, which averages around 6-7 m, under particular atmospheric conditions (low pressure) can even reach $8 \mathrm{~m}$. This drives strong tidal currents (up to $1.4 \mathrm{~ms}^{-1}$ ) in and out of the coast, greatly influencing the sedimentation. Beach sediments consist of fine sands, mainly siliciclastic, and all morphological indicators show a transport direction predominantly from west to east (Hayes et al., 1979; Regnauld et al., 2002; Regnauld et al., 2004).

\section{MATERIALS AND METHODS}

To obtain an updated cartograpy of the Italian test areas, aerial photogrammetric surveys were carried out by UAVs. The DJI INSPIRE 2 was used for the Coastal Dunes Park and the DJI PHANTOM 4 PRO for the WWF Oasis "Bosco Pantano". Flights were carried out from an altitude of 45 meters at a speed of $5 \mathrm{~m} / \mathrm{s}$. To get more detail of the captured images, a front overlap of $90 \%$ and a side overlap of $80 \%$ have been set with respect to the UAV route. The autonomy of the UAVs used was about 30 minutes.

The post-processing of the images was carried out following the Structure from Motion (SfM) technique. It was completed in a Linux environment using the MicMac open source software developed by the French Geographic Institute (IGN). The photogrammetric procedure allowed the creation of a dense point cloud, a depth map (DEM), and a georeferenced orthophoto.

The results obtained constitute a cartographic basis that can be imported and used in the GIS environment for all subsequent processing (Fig. 2).
Before planning the UAV surveys on the French test area, a modelling activity was started that allowed to simulate the coastal area most affected by the stranding oil due to the Amoco Cadiz shipwreck. Subsequently, a flight was carried out with a PARROT SENSEFLY EBEE fixedwing UAV at an altitude of $35 \mathrm{~m}$.

Automatic classification algorithms of RGB images from both UAV and UGV were used in the GIS environment to identify meso-macro beach litter (plastic, glass, metal objects, clots of tar/oil). UGV thermography technique for beach litter was also tested. For stranded oil, multispectral UAV tests were carried out on sand samples from the two Italian test areas, specially polluted by oil. For the thermographic acquisitions, a FLIR C3 thermal imaging camera was used which allowed the acquisition of radiometric thermal images. They were subsequently processed with the FLIR Tools software by setting the emissivity of the sand $(\varepsilon=0.90)$. For the multispectral acquisitions the MAIA multispectral camera (SAL Engineering, Eoptis, Italy) and an incident light sensor were used for the correction of variations in solar radiation.

The ROGER-UGV was custom built starting from design that was performed with both $2 \mathrm{D}$ and $3 \mathrm{D}$ CAD technical drawing software. In the design, the technical aspects were considered in the context of the type of terrain used for the rover but also the dimensions and weights of all the sensors that can be installed and all the informatic and electronic components essential for proper handling. A 3S-11.1 V $5200 \mathrm{mAh}$ LiPo battery was used to power the rover for an autonomy of about 40 minutes at full capacity.

From a structural and mechanical point of view, an
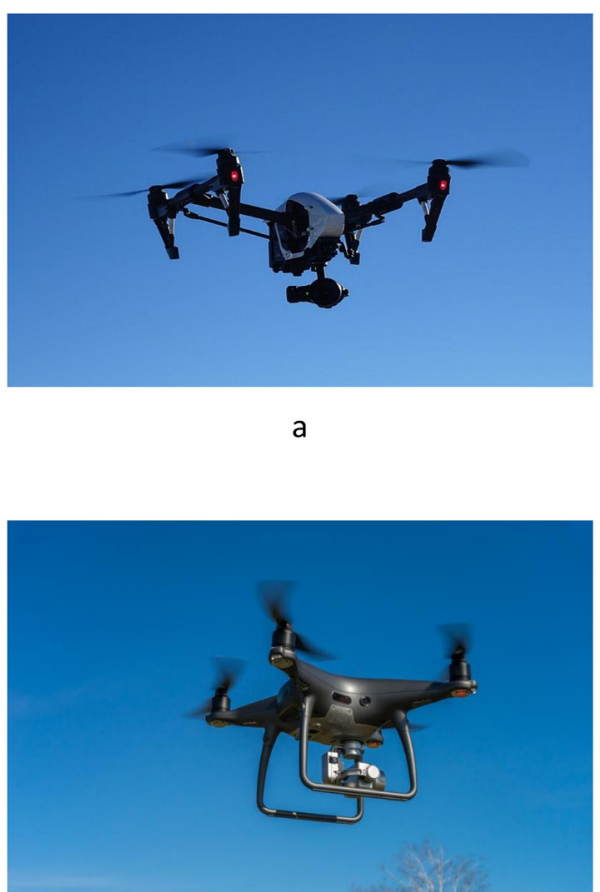

d

\section{Coastal Dunes Park}
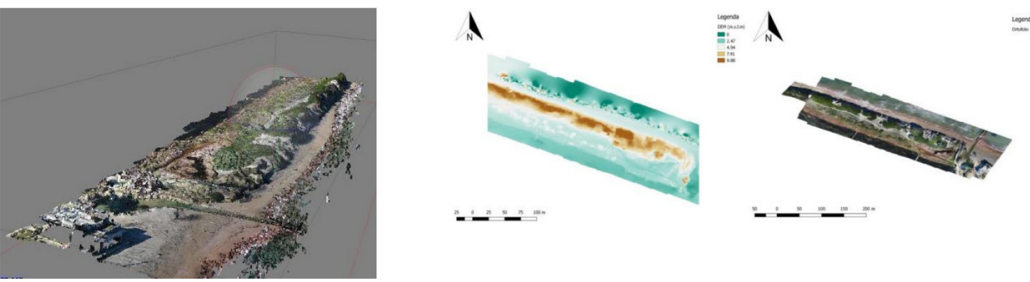

b

WWF Oasis Bosco Pantano

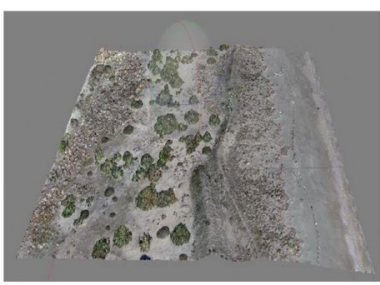

N
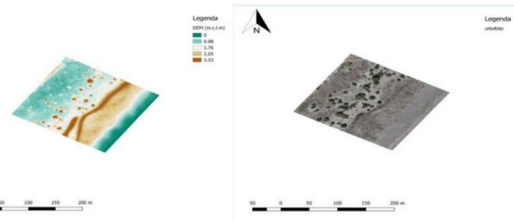

Fig. 2 - Workflow for the cartographic update of the test areas: a) DJI INSPIRE 2 UAV; b) Dense point cloud (Coastal Dunes Park); c) DEM and Orthophoto obtained (Coastal Dunes Park); d) DJI PHANTOM 4 PRO UAV; e) Dense Point Cloud (WWF Oasis "Bosco Pantano"); f) DEM and Orthophoto obtained (WWF Oasis "Bosco Pantano”). 
"open" robotic platform was chosen, that is, adaptable to any research project and/or scientific application. ROGER-UGV is able to move on the ground according to two possible configurations: manual and automatic. The manual configuration permits remote control by an operator with the aid of an $\mathrm{RC}$ radio control that transmits the information to a receiver installed on the rover.

The automatic configuration allows the operator to plan a mission to be carried out by ROGER-UGV thanks to the use of the PixHawk autopilot platform which supports the ArduRover firmware. For both manual and automatic configuration, the operator always has the control of all the information on the operations in progress on a Ground Station. This is a hardware and software platform for the control of remotely piloted systems (UAV-UGV) and allows to perform many operations. In this specific case, a notebook PC was used as the hardware platform for the Ground Station with various open-source software installed.

Besides the components necessary for motion, the UGV was equipped with the FLIR C3 thermal imaging camera that is capable of simultaneously acquiring both thermal and RGB images. Through a Wi-Fi communication network, the thermal imaging camera allows to send the acquisitions to the Ground Station in the form of a radiometric file. Furthermore, if signal is weak or absent, a Matlab code has been implemented that is capable of transforming non-radiometric thermal images, transmitted in video streaming, into radiometric images that can be used in the subsequent processing and interpretation of the data.

Very important was also the installation of an FPV camera on the rover on a special 3D gimbal capable of storing images but above all transmitting in real-time video streaming at a frequency of $5.8 \mathrm{GHz}$ the navigation of the rover, thus allowing the operator to correct and/or modify the route, if necessary, permitting to avoid unexpected obstacles in both manual and automatic modes.

The research activity at the Littoral-EnvironnementTélédétection-Géomatique of Rennes concerned the reconstruction of the environmental disaster of the Amoco Cadiz that occurred in 1978. In particular, through the combination of two numerical modeling software (GNOME - ADIOS) the potential path of the oil spill after the shipwreck of the tanker and subsequently compared with the real route.

GNOME is a software for simulating oil trajectories in the marine environment following oil spills. It was developed by the HAZMAT division of NOAA OR\&R (National Oceanic and Atmospheric Administration Office of Response and Restoration).

ADIOS (Automated Data Inquiry for Oil Spill) is a software developed by NOAA that allows you to appreciate the physico-chemical changes of oil spilled in the marine environment. After having recovered all the information on the weather and sea conditions (present at the time of the disaster) and on the chemical-physical characteristics of the spilled oil, the simulation work was started.

\section{RESULTS AND DISCUSSION}

The realization of the UGV prototype make possible to test both the handling of the rover in beach environments and the acquisition methodology with the various sensors and the subsequent phases of data processing for the identification of pollutants in coastal areas. The results of the Amoco Cadiz oil spill simulation made it possible to estimate the sea surface affected by oil dispersion (about $18,000 \mathrm{~km}^{2}$ ) and the length of the coastal strip of Brittany affected, to a different extent, by oil stranding (about 450 $\mathrm{km}$ ). The greater vulnerability of the coastal strip between Portsall and Lampaul-Ploudalmezeau to oil pollution was ascertained from simulation.

The supervised automatic classification of the RGB images allowed the recognition of three main pixels classes present in the three areas of aerial and ground surveys, namely: sand, vegetation and beach litter. The validation of these results was obtained through the creation of the confusion matrix and the calculation of the kappa coefficient. They were obtained by creating, in a GIS environment, 1000 random points and verifying for each point the correspondence between the truth on the ground and the automatic classification obtained. The images analysis concerned 4 sectors of the Coastal Dunes Park (Fig. 3a) and the calculation of the kappa coefficient showed a satisfactory agreement (kappa> 0.70) between the automatic classification and the truth on the ground verified by the on-site surveys. Only in one area the kappa value was slightly lower (0.68).

In the WWF Oasis "Bosco Pantano" (Fig. 3b) and on the coastal strip of Lampaul - Ploudalmezeau (Fig. 3c), the images analysis concerned 2 sectors and 1 sector respectively. In this case, the kappa coefficients calculated with the confusion matrix in these areas were higher than the minimum value which certifies the excellent agreement between the classification and the truth found directly on-site.

A satisfactory agreement (kappa> 0.70) also emerged from the UGV surveys (Fig. 3d) between the automatic classification and the truth on the ground verified by the on-site surveys. Only in one area the kappa value was lower (0.57).

Furthermore, the average of the kappa coefficients was considered for both the UAV (0.77) and the UGV (0.78) acquisitions concerning the Coastal Dunes Park. A slight improvement in the calculated value was observed, of the order of $1.3 \%$. This slight increase in the kappa coefficient may have been due to the greater proximity between the acquisition sensor (installed on the UGV) and the target (sand, vegetation, beach litter) which, therefore, positively influences the images resolution.

Similarly, the results obtained from the thermographic processing (Fig. 3e) allowed to classify the thermal ranges of each image into three macro classes but did not permit to distinguish with great accuracy the anthropic material present compared to the other elements of the scene (sand and vegetation). In general, it was possible to confirm the tendency of plastic materials to reach lower temperatures than the other natural elements present in the frames and a tendency of ferrous and paper materials to reach higher temperatures than the other natural elements present.

The multispectral tests on the samples of oil-polluted and non-polluted sand have allowed the extrapolation of the reflectance values of each individual band and the construction of a graph that highlights the differences in spectral behavior between the various samples. The most important differences were observed in the different 

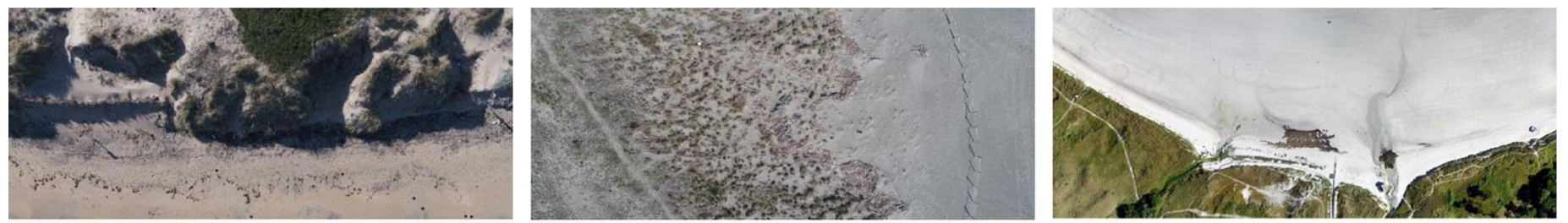

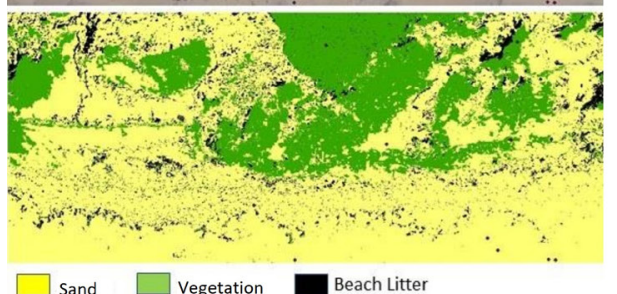

a

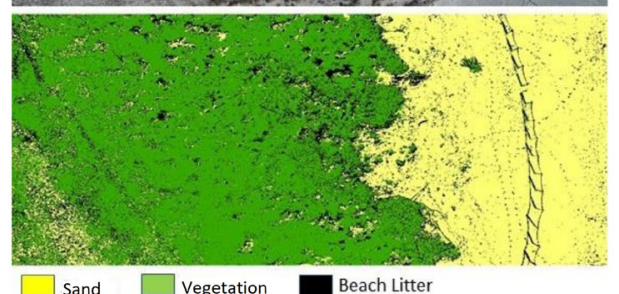

b

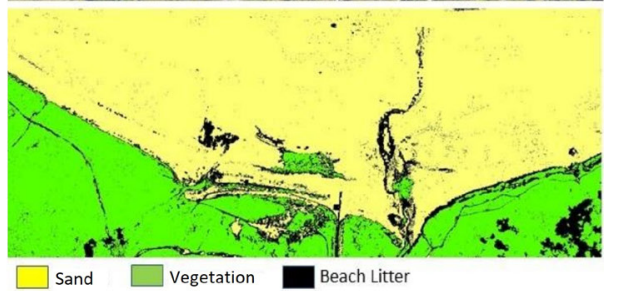

C

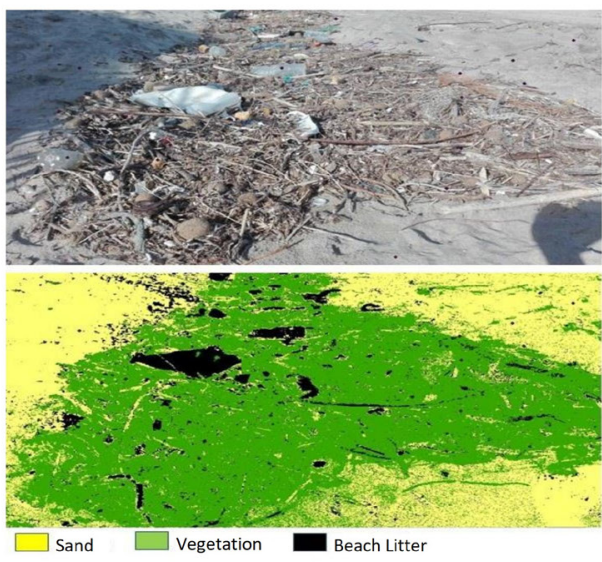

d
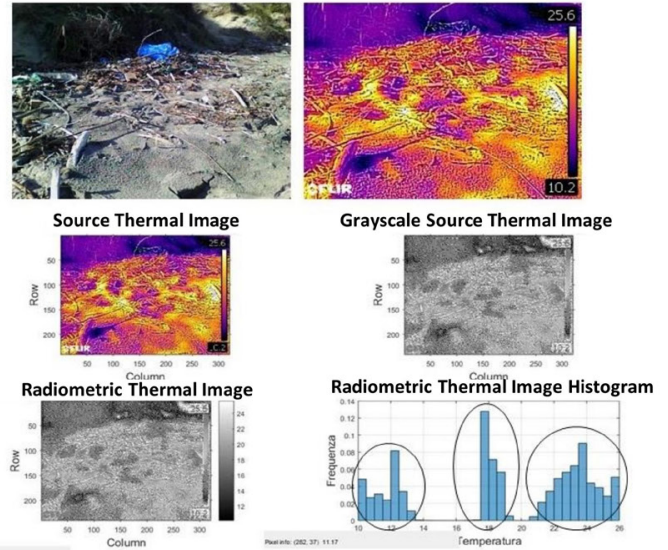

e

Fig. 3 - Some elaborations obtained from the processing: a) Beach litter identification by Automatic RGB Classification (Coastal Dunes Park); b) Beach litter identification by Automatic RGB Classification (WWF Oasis "Bosco Pantano"); c) Beach litter identification by Automatic RGB Classification (Lampaul-Ploudalmezeau coastal strip); d) Beach litter identification by Automatic RGB Classification with UGV surveys; e) Beach litter identification with thermal camera on UGV.

spectral trend within the 9 wavelength bands investigated by the multispectral sensor (Fig. 4a).

In particular, the difference observed in the first 6 bands between the polluted and non-polluted samples allowed the development of a normalized empirical index NDHI (Normalized Difference Hydrocarbon-Oil Index) indicated in the search for oil stranding in beach environments:

\section{$\mathrm{NDHI}=\frac{\text { Band } 6-\text { Band } 1}{\text { Band } 6+\text { Band } 1}$}

Subsequent processing allowed the identification of three threshold values, thus defining the risk level related to the presence of oil-polluted sands in the beach environment.

In particular, the following risk levels are defined:

- Low Risk: NDHI <0.35;

- Moderate Risk: $0.35 \leq \mathrm{NDHI}<0.40$;

- High Risk: NDHI>0.40;
The processing of the multispectral image, acquired during the test and obtained with the UAV survey, and the application on it of the NDHI index (calculated on each pixel) clearly showed the presence of mineral oil in the sand samples (Fig. 4b) of the two test areas (Coastal Dunes Park and WWF Oasis "Bosco Pantano"), artificially contaminated.

These tests have shown the effectiveness of these sensors in identifying possible oily stranding on the beach.

\section{CONCLUSIONS}

After preliminary UAV surveys to define and update the cartography of the test areas to be used with the GIS software, the research activities focused on the design and development of a terrestrial robotic system (UGV) capable of moving in a beach environment and identifying, through the use of suitable sensors and through the methods described (automated image analysis), the possible presence of oil and beach litter. 


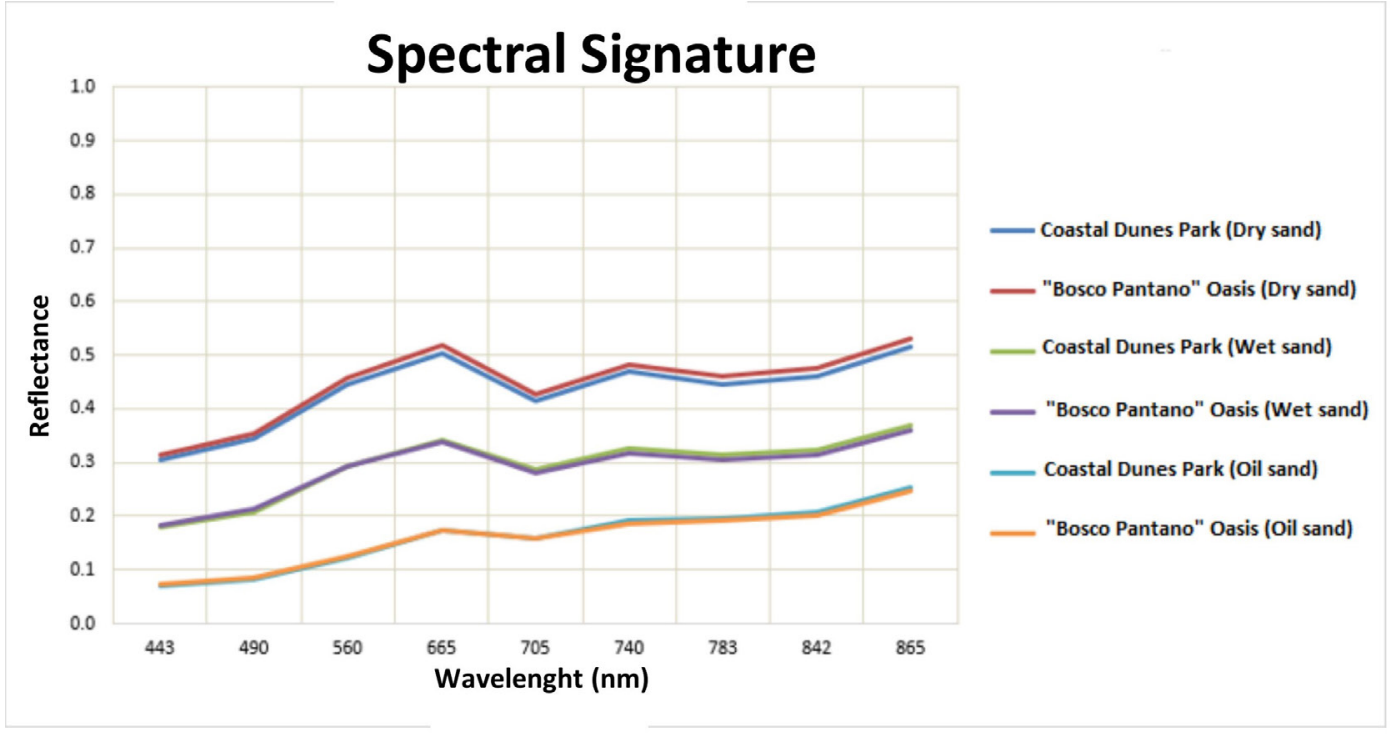

a

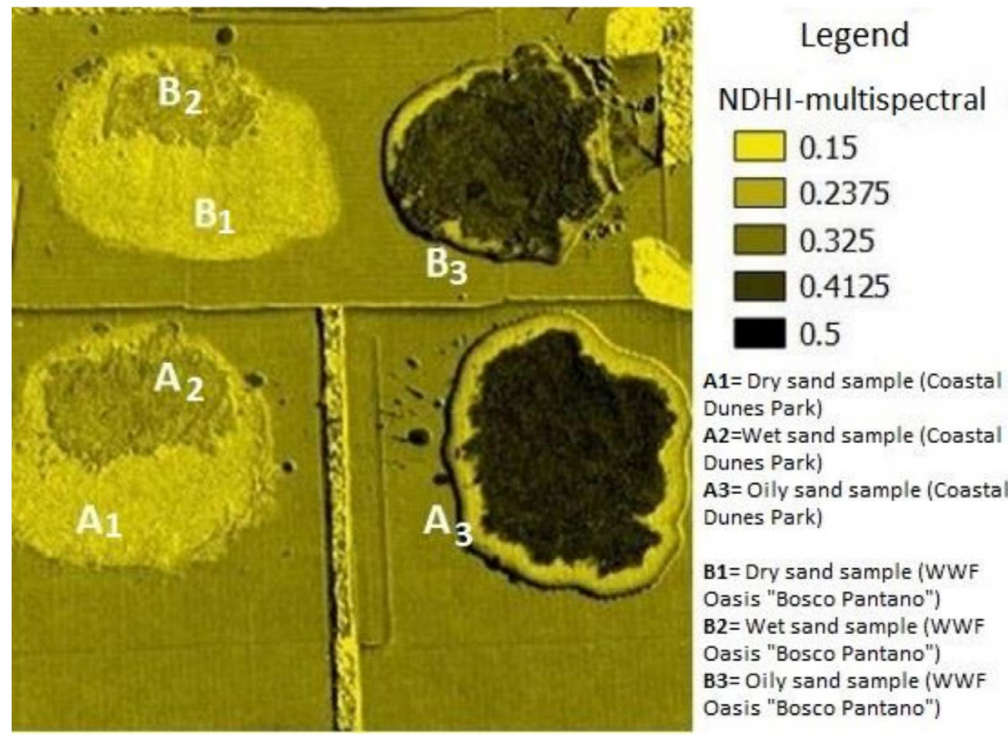

Fig. 4 - Results of multispectral tests on sand samples: a) The graphs describe the spectral signatures and the spectral trend of the sand samples; b) NDHI index values to the obtained multispectral image.
The integrated system consisting of the UGV rover and the installed sensors produced satisfactory results (based on the obtained kappa coefficient) for the identification of the beach litter. In particular, the technique of automatic classification of the acquired RGB images and the ground thermography technique produced the same classification of environments even if the thermographic processing it was found to be less precise and defined.

Further tests with a multispectral sensor made it possible, however, to identify stranded oil on beaches. By exploiting these innovative techniques, it was possible to extract the spectral trend of a typical oil-saturated sand sample by comparing it with an unpolluted sample.

The tested survey methodologies can replace the direct survey performed by man, speeding up identification time. Compared to satellite images, they showed the advantage of having a higher resolution and potentially higher image acquisition frequency.

This research work produced a methodology for the definition of strategy for preliminary assessment of the vulnerability of a given coast to pollution from beach litter (plastic, glass, metal objects, clots of tar/ oil). The research project produced results of double value: ì - technological because a new methodology has been developed for monitoring and analyzing the anthropic impact on coastal systems; ì̀ - applications because a multisensor system has been created that can be used by stakeholders such as: public institutions and private and companies operating in the field of coastal remediation. 


\section{REFERENCES}

Aiello A., Canora F., Pasquariello G. \& Spilotro G. (2013) - Shoreline variations and coastal dynamics: A space-time data analysis of the Jonian littoral, Italy. Estuarine, Coastal and Shelf Science, 129, 124-135.

Atlas R.M., Boehm P.D. \& Calder J.A. (1981) - Chemical and biological weathering of oil, from the Amoco Cadiz spillage, within the littoral zone. Estuarine, coastal and shelf science, 12(5), 589-608.

Belfiore A. (1984) - La dispersione dei sedimenti nel settore occidentale del Golfo di Taranto. Boll. Soc. Geol. It., 103, 415-424.

Benassai E., Cataldo P. \& Ragone A. (1976) - Inquadramento meteomarino dell'area campione dello Ionio. Quaderni de "La Ricerca Scientifica", 94, 3-21.

Brondi A., Ferretti O. \& Anselmi B. (1974) - Deriva delle sabbie del litorale nord-occidentale del Golfo di Taranto. Rend. Soc. It. Min. e Petr., 20, 111-140.

Cagnazzo C., Potente E., Rosato S. \& Mastronuzzi G. (2020) Geostatistics and Structure from Motion Techniques for Coastal Pollution Assessment along the Policoro Coast (Southern Italy). Geosciences, 10, 28.

Cagnazzo C., Potente E., Rosato S., \& Mastronuzzi G. (2020) Numerical modeling for coastal environmental monitoring: oil spills simulation along the lower Adriatic coasts. Rend. Online Soc. Geol. It., 52, 19-24. https://doi.org/10.3301/ROL.2020.12.

Cilumbriello A., Sabato L., Tropeano M., Gallicchio S., Grippa A., Maiorano P., Mateu-Vicens G.. Rossi C.A., Spilotro G. \& Calcagnile L. (2010) - Sedimentology, stratigraphic architecture and preliminary hydrostratigraphy of the Metaponto coastal-plain subsurface (Southern Italy). Mem. Descr. Carta Geol. d'It., 67-84.

Conan G. (1982) - The long-term effects of the Amoco Cadiz oil spill. Phil. Trans. R. Soc. Lond. B297, 323-333.

D’Ozouville L., Gundlach E.R. \& Hayes M.O. (1978) - Effect of coastal processes on the distribution and persistence of oil spilled by the Amoco-Cadiz - Preliminary conclusions. Publications du Centre National pour l'Exploitation des Océans (CNEXO). Série: Actes de colloques, $n^{\circ}$ 6, 1978, pp. 69-96.

De Giglio M., Dubbini M., Cortesi I., Maraviglia M., Parisi E. I. \& Tucci G. (2020) - Plastics waste identification in river ecosystems by multispectral proximal sensing: a preliminary methodology study. Water and Environment Journal, 35(2), 569-579.

De Santis V., Caldara M., Torres T. \& Ortiz J.E. (2018) - A review of MIS 7 and MIS 5 terrace deposits along the Gulf of Taranto based on new stratigraphic and chronological data. Ital. J. Geosci., 137(3), 349-368. https://doi.org/10.3301/IJG.2018.02.

De Santis V., Caldara M., Torres T., Ortiz J.E., \& Sanchez-Palencia Y. (2019) - The role of beach ridges, spits, or barriers in understanding marine terraces processes on loose or semiconsolidated substrates: Insights from the givoni of the Gulf of Taranto (southern Italy). Geol. J., 1-25.

Giuliani C., Veisz A.C. Piccinno M., \& Recantesi F. (2019) Estimating vulnerability of water body using Sentinel-2 images and environmental modelling: the study case of Bracciano Lake (Italy). European Journal of Remote Sensing, 52, suppl. 4, 64-73.

Gundlach E.R., Boehm P.D., Marchand M., Atlas R.M., Ward D.M \& Wolfe D.A. (1983) - The fate of Amoco Cadiz Oil. Science, 221(4606), 122-129.
Hayes M. O., Gundlach E. R. \& D'Ozouville, L. (1979) - Role of dynamic coastal processes in the impact and dispersal of the Amoco Cadiz oil spill (March 1978) Brittany, France. In International Oil Spill Conference, 1979, No. 1, 193-198.

Khanna S., Santos M.J., Ustin S.L., Shapiro K., Haverkamp P.J., \& Lay M. (2018) - Comparing the Potential of Multispectral and Hyperspectral Data for Monitoring Oil Spill Impact. Sensors, 18, 558.

Lega M., \& Napoli R.M.A. (2010) - Aerial infrared thermography in the surface waters contamination monitoring, Desalination and Water Treatment, 23(1-3), 141-151.

Lega M., Kosmatka J., Ferrara C., Russo F., Napoli R.M.A. \& Persechino G. (2012) - Using Advanced Aerial Platforms and Infrared Thermography to Track Environmental Contamination, Environmental Forensics, 13(4), 332-338.

Manning J., Verfaillie M., Barker C., Berg C., MacFadyen A., Donnellan M., Everett M., Graham C., Roe J. \& Kinner N. (2021) - Responder Needs Addressed by Arctic Maritime Oil Spill Modeling. J. Mar. Sci. Eng., 9, 201.

Marchand M., (1980) - The Amoco Cadiz oil spill. Distribution and evolution of hydrocarbon concentrations in seawater and marine sediments. Environment International, 4(5-6), 421-429.

Marchand M., Monfort J. \& Rubio A. (1982) - Distribution of hydrocarbons in water and marine sediments after the Amoco Cadiz and Ixtoc-I. Oil spills in Energy and Environmental. Volume 1 (LH Keith, ed). Ann. Arbor. Science, 487-509.

Mastronuzzi G., Palmentola G. \& Sanso P. (2001) - Evoluzione morfologica della fascia costiera di Torre Canne (Puglia adriatica) Studi Costieri, 4, 19-31.

Mastronuzzi G. \& Sanso P. (2002) - Holocene coastal dune development and environmental changes in Apulia (Southern Italy). Sedimentary Geology, 150, 139-152.

Mastronuzzi, G. Palmentola, G. \& Sansò P. (2002) - Lineamenti dinamica della costa pugliese. Studi Costieri 5, 9-22.

Moretti M., Tropeano M., Van Loon A.J, Acquafredda P., Baldacconi R., Festa V., Lisco S., Mastronuzzi G., Moretti V., \& Scotti R. (2016) - Texture and composition of the Rosa Marina beach sands (Adriatic coast, southern Italy): a sedimentological/ecological approach. Geologos, 22(2), 87-103.

Regnauld H. \& Louboutin R. (2002) - Variability of sediment transport in beach and coastal dune environments, Brittany, France. Sedimentary Geology, 150(1-2), 17-29.

Regnauld H., Pirazzoli P.A., Morvan G. \& Ruz M. (2004) - Impacts of storms and evolution of the coastline in western France. Marine Geology, 210(1-4), 325-337.

Sabato L., Longhitano S.G., Gioia D., Cilumbriello A. \& Spalluto L. (2012) - Sedimentological and morpho-evolution maps of the "Bosco Pantano di Policoro" coastal system (Gulf of Taranto, southern Italy). J. Maps, 8, 304-311.

Sauer D., Wagner S., Brückner H., Scarciglia F., Mastronuzzi G. \& Stahr K. (2010) - Soil development on marine terraces near Metaponto (Gulf of Taranto, southern Italy). Quat. Int., 222, 4863.

Zanier G., Palma M., Petronio A., Roman F. \& Armenio V. (2019) - Oil Spill Scenarios in the Kotor Bay: Results from High Resolution Numerical Simulations. J. Mar. Sci. Eng., 7, 54 